SMALL INTESTINE

\title{
Gut mucosal granulocyte activation precedes nitric oxide production: studies in coeliac patients challenged with gluten and corn
}

\author{
G Kristiánsson, M Högman, P Venge, R Hällgren
}

Gut 2005;54:769-774. doi: 10.1136/gut.2004.057174

\begin{abstract}
See end of article for authors' affiliations

.....................

Correspondence to: Dr G Kristiánsson,

Department of Medical

Sciences, Uppsala

University, Department of

Gastroenterology,

Uppsala University

Hospital, 75185 Uppsala,

Sweden;

gudjon.kristjansson@

medsci.uu.se
\end{abstract}

Revised version received

27 January 2005

Accepted for publication

1 February 2005

\begin{abstract}
Background and aims: To elucidate the dynamics of nitric oxide (NO) production induced by rectal gluten challenge and the relation between NO production and mucosal granulocyte activation.

Subjects and methods: Release of rectal NO was measured in 13 patients with coeliac disease and in 18 controls before and after rectal wheat gluten challenge. Rectal gas was collected with a rectal balloon using a newly developed instrument/technique, the "mucosal patch technique". The instrument allows simultaneous measurements of concentrations of granulocyte mediators in the rectal mucosa. We measured myeloperoxidase (MPO), eosinophil cationic protein (ECP), and histamine. For comparison, we made similar measurements after corn (maize) gluten challenge.

Results: In all coeliac patients rectal NO concentration increased after gluten challenge and reached a peak after 15 hours (mean 9464 (SEM 2393) parts per billion (ppb); range 250-24982). The maximum MPO and ECP increase occurred five hours after challenge. A correlation was found between mucosal MPO and NO production at 15 hours. Six of the patients showed an increase in NO production 15 hours after rectal corn gluten challenge but this was much smaller than after gluten challenge. No increases were seen in the control group after either challenge.

Conclusion: Mucosal activation of neutrophils and eosinophils precedes pronounced enhancement of mucosal NO production after rectal wheat gluten challenge in patients with coeliac disease. Some of our coeliac patients displayed signs of an inflammatory reaction, as measured by $\mathrm{NO}$ and granulocyte markers, after rectal corn gluten challenge.
\end{abstract}

$\mathrm{N}$ itric oxide (NO) production is part of the inflammatory process but its role is uncertain. Some studies indicate a protective role ${ }^{12}$ and others a harmful role. ${ }^{3}$ The dynamics of NO production during acute inflammation have not been elucidated previously. NO is synthesised from L-arginine by the enzyme NO synthase (NOS), ${ }^{4}$ which exists in three isoforms: NOS I (also known as nNOS), NOS II (also known as iNOS), and NOS III (also known as eNOS). ${ }^{5}$ NOS II is the major inducible isoform and may become activated as part of immune and inflammatory responses and produces great amounts of NO as long as the enzyme is activated. In order to elucidate NO production after antigen stimulation, we have studied the gut mucosal reaction to gluten in patients with coeliac disease (CD). Increased luminal NO concentrations in the small intestine have previously been reported in patients with untreated $\mathrm{CD}^{6}$ Although this disease affects predominately the proximal intestine, immune cells reactive to gluten antigens appear to be distributed along the mucosa of the entire gastrointestinal tract. $^{7-9} \mathrm{CD}$ may be considered a prototype T cell mediated disease, being strongly associated with HLA class II and a triggering antigen (wheat gluten and related cereals). ${ }^{10}$ Small intestinal inflammation usually remits on a strict gluten free diet. A novel aspect of the pathogenesis of CD has recently been described by Maiuri and colleagues. ${ }^{11}$ Their data suggest that the adaptive immune reaction induced by gluten can be further driven by gliadin peptides by the less specific innate immune system.

Rectal challenge with gluten induces in coeliac patients a delayed rectal inflammatory reaction, which we studied using a newly developed technique (mucosal patch technique) designed to measure inflammatory substances in the gut mucosa. ${ }^{12}$ This technique also allows simultaneous collection of rectal luminal gas for NO measurements. In the present study, we attempted to elucidate the dynamics of NO production after rectal challenge with gluten as well as the kinetic relationship to mucosal granulocyte activation, defined by luminal concentrations of myeloperoxidase (MPO) and eosinophil cationic protein (ECP).

\section{PATIENTS AND METHODS}

\section{Study subjects}

The study comprised 13 patients (six males, seven females), mean age 48 years (range 25-68), and 18 healthy control subjects ( 13 males, five females), mean age 32 years (range 19-58). Criteria for a diagnosis of CD were: (a) a small intestinal biopsy specimen showing subtotal or partial villous atrophy at the time of the diagnosis and (b) recovery of the histopathology after a gluten free diet. All patients had been on a gluten free diet for an average of 12 years (range 6-22). After a gluten free diet, small intestinal biopsy results were normal (Marsh 0) in 9/13 patients; 4/13 had partial remission (Marsh 1). At the time of the present investigation, all patients had IgA tissue transglutaminase and IgG/IgA gliadin antibodies within the normal range and no detectable IgA endomysial antibodies. All patients with CD had normal blood test results at the time of investigation. Healthy controls had normal blood test values (no signs of inflammation, malabsorption, or disease) and no gastrointestinal symptoms. They had no history of illness during the past year. None of the controls had a rise in IgA antibodies to gliadin or endomysium. One had a border value for IgA

Abbreviations: $C D$, coeliac disease; $N O$, nitric oxide; NOS, NO synthase; MPO, myeloperoxidase; ECP, eosinophil cationic protein; ppb, parts per billion; CTAB, N-Cetyl-N,N,N-trimethyl ammonium bromide 
antibodies to tissue transglutaminase but no other signs of $\mathrm{CD}$ and normal duodenal biopsy results.

All subjects underwent rectal provocation with gluten, and mucosal and blood measurements were performed before and after the challenge. Initially, in 10 of the CD patients, measurements were made before and 5, 24, and 48 hours after rectal gluten challenge. These results indicated the need for a 15 hour measurement, and a further gluten challenge was therefore performed in all patients and measurements were carried out at 15 hours in addition to the other time points. Two patients also underwent a 10 hour test but as the NO peak occurred at 15 hours we decided not to continue with tests at 10 hours. Controls were tested before and 15 hours after the challenge. Ten of the patients and seven of the controls underwent a second test with corn gluten for evaluation of the specificity of the reaction.

The ethics committee of the Medical Faculty, Uppsala University, approved the study. All participants gave informed consent to participate in the study.

\section{Rectal challenge}

Participants were challenged with wheat gluten 6.2-6.5 g (crude wheat gluten; Sigma Chemical Co., St Louis, Missouri, USA) and corn gluten 6.2-6-5 g (corn gluten meal; Sigma Chemical Co.) suspended in $25 \mathrm{ml}$ of $0.9 \% \mathrm{NaCl}$ solution. The suspension was instilled into the rectum with a syringe with the subject lying in the left lateral position. Subjects were then allowed to move about as they wished and were instructed to retain the enema for at least 60 minutes. Rectal challenge was performed between 4 and $6 \mathrm{pm}$ and measurements 15 hours later, between 7 and 9 am. Subjects were told to fast for one hour before the challenge and one hour after the challenge and also from midnight before the measurements.

\section{Preparation}

All patients and controls were given a rectal enema (Klyx $120 \mathrm{ml}$; Ferring, Copenhagen, Denmark) within one hour before introduction of the instrument.

\section{Mucosal evaluation}

To elucidate inflammation after the rectal challenge with gluten, we measured inflammatory mediators of neutrophil activity (MPO), eosinophil activity (ECP), and histamine using a new instrument, a polyethylene catheter with a silicon balloon at its end, and with three patches attached to the balloon. ${ }^{12}$ The instrument for the mucosal patch technique has been described previously and has been found to be rapid, simple, safe, and highly sensitive, and to produce reliable and reproducible data concerning mucosal inflammatory markers. The patches were made of highly absorptive cellulose material (Pharmacia Diagnostics AB, Uppsala, Sweden). When the instrument was positioned in the rectum, the balloon was inflated with air $(60-80 \mathrm{ml})$, allowing the patches to come into contact with the mucosa. Two latex shields protected the patches during introduction of the catheter into the rectum and when it was retracted. If the patient had a strong feeling of distension or pain that did not disappear after 2-3 minutes, the volume of air was reduced by $5 \mathrm{ml}$ at a time until the catheter and balloon were accepted. A minimum of $50 \mathrm{ml}$ of air were left in the balloon to ensure that the patches adhered to the mucosa. The balloon was kept inflated for 20 minutes in all subjects, after which time it was deflated and the catheter removed. The patches were cut off and immediately put into $2 \mathrm{ml}$ of $0.3 \%$ CTAB (N-Cetyl-N,N,N-trimethyl ammonium bromide; E Merck, Darmstadt, Germany) solution to extract the contents. Any discomfort, reactions, or other symptoms during the test procedure were recorded, as was the presence of any blood or faeces on the patches.

Each patch was collected and analysed separately. Patches were kept in the $0.3 \%$ CTAB solution for extraction for one hour. After completion of this step, the extraction solution was squeezed out of the patches, centrifuged, and frozen at $-70^{\circ} \mathrm{C}$ until analysed.

Duplicate samples were analysed, using radioimmunoassays to measure concentrations of MPO, ECP, and histamine, according to the manufacture's instructions (Pharmacia Diagnostics AB, Uppsala, Sweden).

\section{NO measurements}

NO was measured with a chemiluminescence NO analyser (model Sievers NOA 280; Ionics Instrument Business Group, Boulder, Colorado, USA). The system was calibrated with a mixture of $\mathrm{NO}$ in $\mathrm{N}_{2}$ (AGA Gas AB, Lidingö, Sweden) with an NO concentration of 500 parts per billion (ppb). The calibration was tested every morning and zero was set before each measurement. Air samples were collected with three glass syringes from the cuff of the rectal catheter described above. Each sample was measured separately. Air was injected into the NO analyser and the peak level was monitored. The single measure for each subject represents the highest value obtained in the collected air samples to avoid false low NO measurement due to syringe leakage. An extraction test was performed to see how much NO could be recovered with our instrument and it was found that $80 \%$ was recovered (data not shown), a result in accordance with earlier reports. ${ }^{13}$

\section{Statistics and calculations}

Results are presented as mean (SEM) (range). The Mann Whitney U test, Friedman ANOVA, sign test, and Spearman's sign rank test were used for statistical calculations.

\section{RESULTS}

\section{Gluten challenge and NO production}

The prechallenge rectal luminal NO value in patients with CD was 19 (4) ppb (range 6-41) and in controls 24 (6) ppb (6-90). No relation to age or sex was seen in patients or controls. The results of gluten challenge in patients with CD are illustrated in fig 1 . No NO production was detected five hours after the challenge. The maximum NO concentration (9464 (2393) ppb; range 250-24982) was noted after 15 hours. NO values then gradually declined but had not returned to normal in all patients by 48 hours. Mean NO production in controls 15 hours after rectal gluten challenge

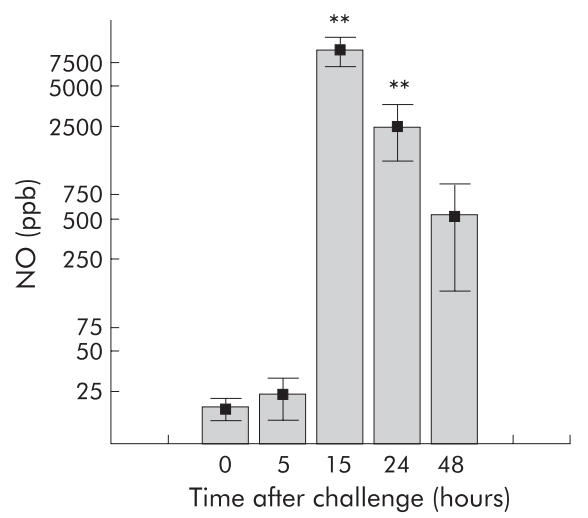

Figure 1 Rectal luminal nitric oxide (NO) before and 5, 15, 24, and 48 hours after rectal gluten challenge in 10 patients with coeliac disease (mean (SEM)). Friedman ANOVA was significant $(p<0.001) ;{ }^{* *} p<0.01$ compared with prechallenge value (sign test). ppb, parts per billion. 


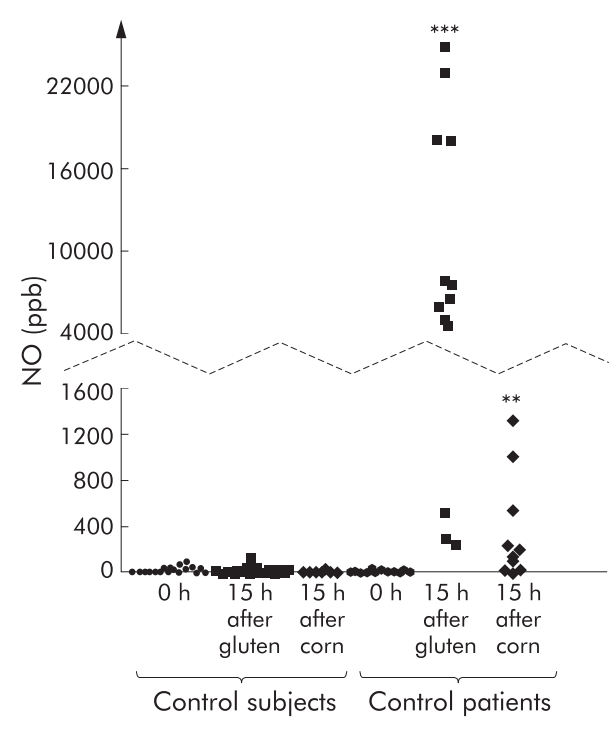

Figure 2 Rectal concentrations of nitric oxide (NO) in 18 controls and 13 coeliac patients before challenge $(0 \mathrm{~h}), 15$ hours after rectal wheat gluten challenge ( $15 \mathrm{~h}$ after gluten), and 15 hours after rectal corn gluten challenge ( $15 \mathrm{~h}$ after corn). Note that the $\mathrm{Y}$ scale is broken, highlighting the differences between the two sections, and better illustrating the lower values. Significant increase was found when the patient and control groups were compared using the Mann-Whitney $U$ test: ${ }^{* *} p<0.01,{ }^{* * *} p<0.001$.

was 22 (7) ppb (range 4-126). Rectal NO concentration in two patients with CD who were tested 10 hours after the challenge was almost half of that seen at 15 hours in the same patients.

\section{Corn challenge and NO production}

In CD patients, NO production 15 hours after corn challenge was significantly increased by a mean of 368 (147) ppb (range 13-1348) compared with the prechallenge value $(p<0.05)$. However, as seen in fig 2 , only $6 / 10$ patients showed a postchallenge increase in NO. The relative increase was considerably greater after gluten challenge (on average 500 -fold) than after corn challenge (on average 15 -fold). In controls, no increase in NO was seen after corn challenge (fig 2.)

\section{Relation of NO production to signs of granulocyte and mast cell/basophil activation \\ Gluten challenge}

The kinetic responses of neutrophil activation in CD patients, assessed as release of MPO, are illustrated in fig 3B. In contrast with NO production, strong signs of neutrophil activation were already seen five hours after gluten challenge. After the initial increase, the concentration of MPO remained elevated throughout the observation period of 48 hours. There was a significant correlation $(r=0.64, \mathrm{p}<0.05)$ between the increases in MPO $(\triangle \mathrm{MPO})$ and the increase in $\mathrm{NO}(\Delta \mathrm{NO}) 15$ hours after the challenge (fig $3 \mathrm{~A})$. The kinetics of eosinophil activation, as represented by ECP values, is also illustrated (fig 3C). No correlation was found between $\triangle \mathrm{ECP}$ and $\Delta \mathrm{NO}$, five and 15 hours after the challenge, with $\mathrm{r}$ values of 0.02 and 0.04 , respectively. In controls, gluten induced no increase in MPO or ECP values; prechallenge values were 24 (6) $\mu \mathrm{g} / \mathrm{l}$ (range 6-90) and 33 (7) $\mu \mathrm{g} / \mathrm{l}(2-100)$ and postchallenge values $22(7) \mu \mathrm{g} / \mathrm{l}$ (range 4-126) and 42 (12) $\mu \mathrm{g} / \mathrm{l}$ (range 2-168), respectively.

No increase was found in methyl histamine at five or 15 hours after rectal gluten challenge in patients or controls. Prechallenge values in coeliac patients were $0.4(0.03) \mu \mathrm{g} / \mathrm{l}$ (range 0.3-0.7) and in controls $0.5(0.1) \mu \mathrm{g} / \mathrm{l}(0.2-1.1)$; five hours after the gluten challenge values were $1.3(0.2) \mu \mathrm{g} / \mathrm{l}$ (range 0.7-2.6) and $1.2(0.1) \mu \mathrm{g} / \mathrm{l}(1.0-1.3)$, respectively. At 15 hours values were $1.0(0.2) \mu \mathrm{g} / \mathrm{l}$ (range $0.3-2.1$ ) in coeliac patients and $1.0(0.1) \mu \mathrm{g} / \mathrm{l}(0.3-1.8)$ in controls.

\section{Corn challenge}

Corn challenge also induced an increase in MPO in some patients but the increase was not significant in the coeliac
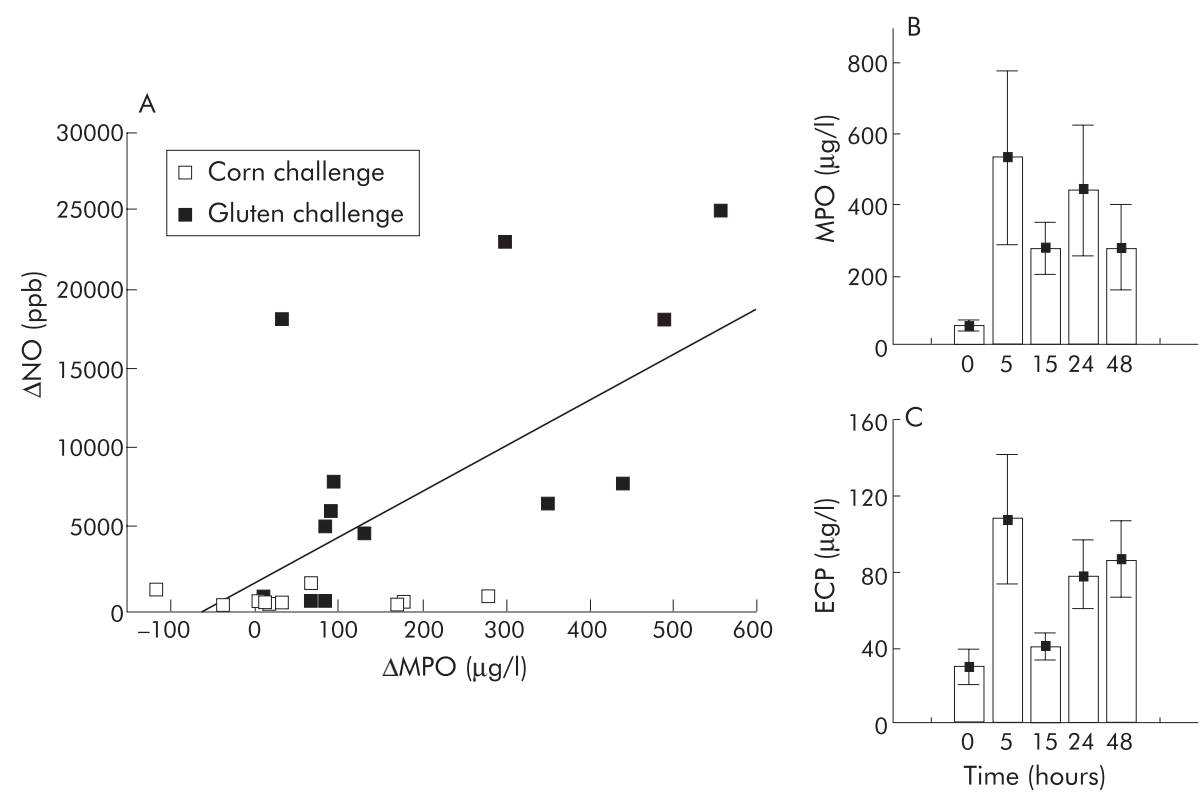

Figure 3 Rectal mucosal nitric oxide (NO) production in patients with coeliac disease. (A) Relation between the increase in $N O(\triangle N O)$ and the increase in mucosal myeloperoxidase ( $\triangle \mathrm{MPO}$ ) 15 hours after gluten and corn challenge. The correlation was significant (Spearman rank order correlation, $r=0.58, p<0.05$ ). Mean (SEM) rectal mucosal MPO (B) and eosinophil cationic protein (ECP) (C) concentrations before and 5, 15, 24, and 48 hours after gluten challenge in 10 coeliac patients for comparison. Friedman ANOVA was significant for both ECP and MPO ( $<<0.05$ ). $p<0.05$ and $p<0.01$ compared with prechallenge values (0 hours) (sign test). 
patients ( $\mathrm{p}>0.05)$; mean baseline MPO value was 64 (17) $\mu \mathrm{g} / \mathrm{l}$ (range 6-188) and $136(42) \mu \mathrm{g} / \mathrm{l}(18-411)$ after 15 hours. Baseline ECP values were 29 (7) $\mu \mathrm{g} / \mathrm{l}$ (range $1-102$ ) and postchallenge ECP values were 36 (6) $\mu \mathrm{g} / \mathrm{l}(5-74)(\mathrm{p}>0.05)$. Control subjects showed no increase in MPO or ECP after the challenge.

\section{DISCUSSION}

In this study we performed a kinetic analysis of gut mucosal NO production in relation to the local inflammatory response induced by instillation of wheat gluten into the rectum of patients with CD. This was made possible by the use of a newly developed technique (mucosal patch technique) that allows simultaneous measurements of $\mathrm{NO}$ and granule proteins released from inflammatory cells into the gut lumen. The obvious advantage of this approach is the gentle handling of the mucosa and the reduced distress for the patient compared with a study with repeated rectal biopsies, which also in fact, might influence NO synthesis. ${ }^{14}$ Our main finding was that signs of granulocyte activation clearly preceded the increased synthesis of NO after gluten challenge. Increased NO synthesis was not apparent five hours after gluten instillation, a time point with maximum release of MPO, a granule constituent of neutrophils, and of ECP, a granule constituent of eosinophils. Luminal NO values peaked 15 hours after gluten challenge and then gradually declined, but were still increased after 48 hours. The granulocyte activation pattern described a biphasic pattern compatible with previous histological findings reporting a biphasic mucosal influx of neutrophils after rectal gluten challenge in coeliac patients. ${ }^{7}$ This pattern might possibly reflect the fact that the gluten induced reaction involves both the adaptive as well as the innate system. ${ }^{11}$

NO is generated via NOS which has constitutive and inducible isoforms. The constitutive isoform of NOS (cNOS) is calcium dependent and involved in various physiological conditions. In response to physiological stimulation, for example of endothelial cells and neurones, NO is generated rapidly and transiently at low concentrations for purposes such as relaxation of vascular smooth muscle cells leading to vasodilatation and inhibition of leucocyte and platelet adhesion to vascular endothelium. The major inducible isoform of NOS (NOS II) produces NO in high concentrations for as long as the enzyme is activated as part of immune and inflammatory responses. This isoform is constitutively present in the epithelium of some tissues but is mainly expressed by inflammatory cells (macrophages, eosinophils, mast cells, and possibly also neutrophils and $\mathrm{T}$ lymphocyte ${ }^{15-19}$ ) on activation by proinflammatory cytokines and other inflammatory mediators. The role of NOS II in the inflammatory response to gluten instillation in the rectal mucosa has previously been elucidated by measurement of rectal mucosal biopsy samples obtained 4, 8, 24, and 48 hours after rectal gluten challenge. ${ }^{20}$ A significant (approximately 50\%) increase in NOS II was seen eight hours after gluten challenge but there was no change in cNOS. Increased NO production in the gut lumen has been observed not only in ulcerative colitis ${ }^{21}$ but also 24 hours after gluten challenge in patients with $\mathrm{CD}^{22}$ Our finding of high production of NO starting 5-10 hours after gluten challenge is in accordance with the above mentioned biopsy results concerning NOS II expression, ${ }^{20}$ as this expression has been found to precede the production of NO by several hours; the delay in NO production reflecting the time taken for mRNA and protein synthesis. ${ }^{23}{ }^{24}$ NOS II expression in rectal biopsy specimens gradually decreased and was lost 24-48 hours after challenge. Our NO measurements showed a return to prechallenge NO values in $30 \%$ of our patients but elevated NO values still remained in a few patients even 48 hours after the challenge. In bronchial asthma an increase in luminal airway $\mathrm{NO}$ is also seen and it has been suggested that this may be useful for non-invasive determination of airway inflammation. ${ }^{25}$ After allergen challenge in asthmatic patients, no increase in NO was observed in those who responded only with an acute reaction, while those who also had a late allergic response had a peak increase in $\mathrm{NO}$ at 10 hours and still showed elevated NO levels 21 hours after the challenge. The similarity to our NO reaction strengthens the idea that gut and airway luminal NO production might be a nonspecific inflammatory response.

The cellular source of induced luminal NO synthesis has not been identified in asthmatic patients. There is evidence of increased expression of NOS II in asthmatic airways, especially in macrophages and epithelial cells, but activated neutrophils, eosinophils, and mast cells have also been proposed as major contributors to enhanced NO synthesis. ${ }^{17}{ }^{26} 27$ The early inflammatory reaction induced by gluten in patients with $\mathrm{CD}$ is characterised by expression of Eselectin, a specific adhesion molecule that is the main mediator involved in neutrophil recruitment in the first four hours after gluten exposure. ${ }^{28}$ This is in concordance with our observations that a strong neutrophil activation, as assessed by luminal release of MPO, and less pronounced eosinophil activation, as measured by release of ECP, was already present five hours after the gluten instillation challenge and clearly preceded the NO response.

Gluten induced small intestinal mucosal inflammation is known to be patchy. Our technique is designed to reduce the influence of an uneven distribution of inflammatory signals by allowing measurements at different mucosal sites. Nevertheless, the observed interindividual variability in NO and MPO responses may partly be due to non-homogenous inflammation. Another, perhaps more likely, explanation is individual sensitivity. ${ }^{29}$ The finding of a significant correlation between neutrophil and NO responses after challenge demonstrates that NO synthesis is linked to the intensity of the induced inflammatory reaction, but only suggests that neutrophils are the cellular NO source.

NO in exhaled air (eNO) has been proposed as a marker of bronchial inflammation. Some studies reported a significant association in patients with bronchial asthma between eNO and airway eosinophilia, as reflected by sputum eosinophilia $^{30}{ }^{31}$ or density of eosinophilic granule constituents in airway mucosa. Because eosinophils can express NOS II, ${ }^{32}$ these cell have been attributed a role in the synthesis of NO after allergen challenge. However, others have been unable to confirm a relationship between eNO and airway eosinophilia in asthma. ${ }^{33}{ }^{34}$ In the present study, signs of eosinophil activation, as reflected by ECP, were present after gluten challenge in patients with CD, with a similar time course of activation as neutrophils, but the eosinophil response was relatively weaker than the neutrophil response defined by MPO. The lack of relationship between the degree of eosinophil activation and NO production may suggest that NO reflects other aspects of gut mucosal inflammation, including neutrophil and possibly also $\mathrm{T}$ cell and monocyte activation.

The site of NOS II expression in the epithelium of gluten damaged rectal mucosa is controversial but immunohistochemical studies of such mucosa showed that NOS II was mostly localised in the lamina propria just beneath the surface epithelium and around the crypts. ${ }^{20}$ The suggested protective effect of $\mathrm{NO}$ in inflammation has been partly attributed to a role in reducing granulocyte infiltration and consuming oxygen species. ${ }^{3}$ Thus the observed relationship between signs of neutrophil activation and later NO synthesis may well reflect a counteracting system controlling the potentially tissue damaging principles delivered by activated 
neutrophils. However, reports suggesting a protective role of $\mathrm{NO}$ in mucosal inflammatory damage are as numerous as those supporting a toxic role. It has been proposed, for example, that NO may promote inflammation by enhancing vascular permeability and by promoting chemotaxis of granulocytes and the production of proinflammatory cytokines. ${ }^{35}{ }^{36}$ Others have suggested that epithelial cells are the cellular source of luminal NO seen in bronchial asthma and inflammatory bowel diseases. ${ }^{37} 38$ Our kinetic study is compatible with this hypothesis as activated granulocytes may induce enterocytes to increase NO synthesis. The results of our study give no answers concerning the possible toxic or protective role of $\mathrm{NO}$ in gluten induced damage. The possibility also remains that the association between granulocyte activation and NO production merely reflects the metabolic expression of neutrophils/ eosinophils and other inflammatory cells activated by gluten challenge.

The lack of luminal histamine release after gluten challenge indicates that mast cells/basophils are not involved in induced NO synthesis. Niveloni et al observed in biopsy samples that the number of NOS II positive cells after gluten exposure increased in parallel with the CD3 cell infiltration observed around the subepithelial areas. ${ }^{20} \mathrm{~T}$ cells have been attributed a central role in the pathogenesis of gluten induced mucosal damage but the NO producing capacity of $\mathrm{T}$ cells in inflammation remains unsolved.

The observation that corn gluten challenge induced an abnormal NO reaction in some of our patients with CD is intriguing as maize is considered safe and is recommended as the substitute cereal in a gluten free diet. However, a high incidence of serum antibodies against maize ${ }^{39}$ has been reported in $\mathrm{CD}$, and failure to normalise the mucosa in a fraction of adult patients with CD and on a strict wheat gluten free diet remains to be explained. ${ }^{40}$ The manufacturer claimed that their corn product was free from wheat or other cereals. We tested the product at the Swedish National Food Administration (Livsmedelsverket) and it was found to be contaminated with $82 \mu \mathrm{g} / \mathrm{g}$ (ppm), which is less than the usual allowed amount in a gluten free diet $(<200 \mathrm{ppm})$ according to the Codex Alimentarius Standard for gluten free foods, and far less than what has been found to be a safe amount of gluten contamination when correlated with histology in oral challenge studies. ${ }^{41}$ It cannot be excluded that the small amounts of gluten present in the corn preparation induced an inflammatory reaction as the mucosal patch technique is very sensitive.

The major finding in the present study was that mucosal activation of neutrophils and eosinophils precedes pronounced enhancement of mucosal NO production after rectal wheat gluten challenge in $\mathrm{CD}$. The observations were made possible by the use of a simple and safe procedure, which may also be of value for elucidating the possible role of other food antigens, such as milk and egg proteins, that may cause symptoms and mucosal damage in some patients with CD.

\section{ACKNOWLEDGEMENTS}

We acknowledge the technical assistance of Sneh Ajuha, Kerstin Lindblad, Åsa Lidman, Karin Fagerbrink, and Agneta Roneus. This work was supported by the Medical Faculty of the University of Uppsala, Sweden, Pharmacia Diagnostics AB, Uppsala, Sweden, Alimenta Diagnostics AB, Uppsala, Sweden, the Vardal Foundationthe Swedish Foundation for Health Care Sciences and Allergy Research, and the Swedish Rheumatism Association.

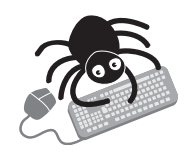

Conflict of interest: declared (the declaration can be viewed on the Gut website at http://www.gut.com/ supplemental).

\section{Authors' affiliations}

G Kristiánsson, Department of Gastroenterology, Uppsala University Hospital, Uppsala, Sweden

M Högman, Department of Medical Cell Biology, Section of Integrative Physiology, Uppsala University Hospital, Uppsala, Sweden

P Venge, Laboratory for Inflammation Research, Uppsala University

Hospital, Uppsala, Sweden

R Hällgren, Department of Rheumatology, Uppsala University Hospital, Uppsala, Sweden

\section{REFERENCES}

1 Pfeiffer CJ, Qiu BS. Effects of chronic nitric oxide synthase inhibition on TNBinduced colitis in rats. J Pharm Pharmacol 1995;47:827-32.

2 Rachmilewitz D, Karmeli F, Okon E, et al. Experimental colitis is ameliorated by inhibition of nitric oxide synthase activity. Gut 1995;37:247-55.

3 McCafferty DM, Mudgett JS, Swain MG, et al. Inducible nitric oxide synthase plays a critical role in resolving intestinal inflammation. Gastroenterology 1997;112:1022-7.

4 Moncada S, Higgs A. The L-arginine-nitric oxide pathway. N Engl J Med 1993;329:2002-12.

5 Moncada S, Higgs A, Furchgott R. International Union of Pharmacology Nomenclature in Nitric Oxide Research. Pharmacol Rev 1997:49:137-42.

6 Everts B, Stotzer P, Olsson M, et al. Increased luminal nitric oxide concentrations in the small intestine of patients with coeliac disease. Eur J Clin Invest 1999:29:692-6.

7 Loft DE, Marsh MN, Sandle Gl, et al. Studies of intestinal lymphoid tissue. XII. Epithelial lymphocyte and mucosal responses to rectal gluten challenge in celiac sprue. Gastroenterology 1989;97:29-37.

8 Torre $\mathbf{P}$, Fusco S, Quaglia F, et al. Immune response of the coeliac nasal mucosa to locally-instilled gliadin. Clin Exp Immunol 2002;127:513-18.

9 Lahteenoja $\mathrm{H}$, Maki M, Viander $\mathrm{M}$, et al. Local challenge of oral mucosa with gliadin in patients with coeliac disease. Clin Exp Immunol 2000;120:38-45.

10 Schuppan D. Current concepts of celiac disease pathogenesis. Gastroenterology 2000;119:234-42.

11 Maiuri L, Ciacci C, Ricciardelli I, et al. Association between innate response to gliadin and activation of pathogenic T cells in coeliac disease. Lancet 2003;362:30-7.

12 Kristiansson G, Venge P, Wanders A, et al. Clinical and subclinical intestinal inflammation assessed by the mucosal patch technique: studies of mucosal neutrophil and eosinophil activation in inflammatory bowel diseases and irritable bowel syndrome. Gut 2004;53:1806-12.

13 Herulf $\mathbf{M}$, Liung T, Hellström PM, et al. Increased luminal nitric oxide in inflammatory bowel disease as shown with a novel minimally invasive method. Scand J Gastroenterol 1998;33:164-9.

14 Miller MJ, Zhang XJ, Sadowska-Krowicka H, et al. Nitric oxide release in response to gut injury. Scand J Gastroenterol 1993;28:149-54.

15 Thomassen MJ, Kavuru MS. Human alveolar macrophages and monocytes as a source and target for nitric oxide. Int Immunopharmacol 2001;1:1479-90.

16 lijima H, Duguet A, Eum SY, et al. Nitric oxide and protein nitration are eosinophil dependent in allergen-challenged mice. Am J Respir Crit Care Med 2001; 163:1233-40

17 Forsythe P, Gilchrist $M$, Kulka M, et al. Mast cells and nitric oxide: control of production, mechanisms of response. Int Immunopharmacol $2001 ; 1: 1525-41$.

18 Armstrong $\mathbf{R}$. The physiological role and pharmacological potential of nitric oxide in neutrophil activation. Int Immunopharmacol 2001;1:1501-12.

19 Kamimura Y, Fujii T, Kojima H, et al. Nitric oxide (NO) synthase mRNA expression and $\mathrm{NO}$ production via muscarinic acetylcholine receptormediated pathways in the CEM, human leukemic T-cell line. Life Sci 2003;72:2151-4.

20 Niveloni S, Weksler-Zangen S, Pedreira S, et al. Time course of nitric oxide synthase generation after gluten exposure in the rectal mucosa of glutensensitive patients. Scand J Gastroenterol 2000;35:1150-6.

21 Grisham MB, Pavlick KP, Laroux FS, et al. Nitric oxide and chronic gut inflammation: controversies in inflammatory bowel disease. J Investig Med 2002;50:272-83

22 Herulf $M$, Blomquist $L$, Liung $T$, et al. Increased rectal nitric oxide in coeliac disease after local challenge with gluten. Scand J Gastroenterol 2001;36:169-73

23 Forstermann U, Pollock JS, Tracey WR, et al. Isoforms of nitric-oxide synthase: purification and regulation. Methods Enzymol 1994;233:258-64.

24 Nathan C, Xie QW. Nitric oxide synthases: roles, tolls, and controls. Cell 1994;78:915-18.

25 Fischer A, Folkerts G, Geppetti P, et al. Mediators of asthma: nitric oxide. Pulm Pharmacol Ther 2002;15:73-81.

26 Barnes PJ, Belvisi MG. Nitric oxide and lung disease. Thorax 1993;48: 1034-43.

27 Payne DN, Adcock IM, Wilson NM, et al. Relationship between exhaled nitric oxide and mucosal eosinophilic inflammation in children with difficult asthma, after treatment with oral prednisolone. Am J Respir Crit Care Med $2001 ; 164: 1376-81$

28 Ensari A, Ager A, Marsh MN, et al. Time-course of adhesion molecule expression in rectal mucosa of gluten-sensitive subjects after gluten challenge. Clin Exp Immunol 1993;92:303-7.

29 Kumar PJ, O'Donoghue DP, Stenson K, et al. Reintroduction of gluten in adults and children with treated coeliac disease. Gut 1979;20:743-9. 
30 Horvath I, Donnelly LE, Kiss A, et al Combined use of exhaled hydrogen peroxide and nitric oxide in monitoring asthma. Am J Respir Crit Care Med 1998; 158:1042-6.

31 Jatakanon A, Lim S, Kharitonov SA, et al. Correlation between exhaled nitric oxide, sputum eosinophils, and methacholine responsiveness in patients with mild asthma. Thorax 1998;53:91-5.

32 del Pozo V, de Arruda-Chaves E, de Andres B, et al. Eosinophils transcribe and translate messenger RNA for inducible nitric oxide synthase. J Immunol 1997; 158:859-64

33 Lim S, Jatakanon A, Meah S, et al. Relationship between exhaled nitric oxide and mucosal eosinophilic inflammation in mild to moderately severe asthma. Thorax 2000;55:184-8

34 Jatakanon A, Uasuf C, Maziak W, et al. Neutrophilic inflammation in severe persistent asthma. Am J Respir Crit Care Med 1999;160:1532-9.

35 Clancy RM, Amin AR, Abramson SB. The role of nitric oxide in inflammation and immunity. Arthritis Rheum 1998;41:1141-51.
36 Lander HM. An essential role for free radicals and derived species in signal transduction. FASEB J 1997; 11:118-24.

37 Hamid Q, Springall DR, Riveros-Moreno V, et al. Induction of nitric oxide synthase in asthma. Lancet 1993:342:1510-13.

38 Singer II, Kawka DW, Scott S, et al. Expression of inducible nitric oxide synthase and nitrotyrosine in colonic epithelium in inflammatory bowel disease. Gastroenterology 1996;111:871-85.

39 Troncone R, Auricchio S, De Vincenzi M, et al. An analysis of cereals that react with serum antibodies in patients with coeliac disease. J Pediatr Gastroenterol Nutr 1987:6:346-50.

40 Faulkner-Hogg KB, Selby WS, Loblay RH. Dietary analysis in symptomatic patients with coeliac disease on a gluten-free diet: the role of trace amounts of gluten and non-gluten food intolerances. Scand J Gastroenterol 1999;34:784-9.

41 Collin P, Thorell L, Kaukinen K, et al. The safe threshold for gluten contamination in gluten-free products. Can trace amounts be accepted in the treatment of coeliac disease? Aliment Pharmacol Ther 2004;19:1277-83.

\section{EDITOR'S QUIZ: GI SNAPSHOT}

\section{An unusual cause of pyrexia}

\section{Clinical presentation}

A 58 year old male patient presented with a 24 hour history of nausea, vomiting, and right shoulder tip pain with associated rigors. On examination he was tachycardic, 100 beats per minute, and pyrexial $\left(38^{\circ} \mathrm{C}\right)$ but clinical examination was otherwise unremarkable. He was taking no medications and the only previous medical history of note related to a large birthmark on his leg which had been investigated when he was a child but had not required intervention. Initial laboratory investigations were also within normal limits apart from an elevated white cell count of $15.5 \times 10^{9} / \mathrm{l}$ and an elevated serum alkaline phosphatase of $256 \mathrm{U} / \mathrm{l}$ (normal range 44-132).

A chest radiograph revealed no focal lung lesion. Blood cultures were obtained prior to commencement of antibiotic therapy and Streptococcus pneumoniae was isolated, the source of which was unclear. In view of the abnormal liver function, ultrasound of the liver was undertaken and this demonstrated a $9 \mathrm{~cm}$ hyperechoic mass in the right lobe atypical for an abscess and suggestive of a tumour. The patient proceeded to computed tomography of the upper abdomen for further assessment and an unenhanced section through the right lobe of the liver and spleen is shown in fig 1 .

\section{Question}

What abnormalities are present? What is the explanation for the bacteraemia? What is the likely diagnosis?

See page 802 for answer
Robin Spiller, Editor

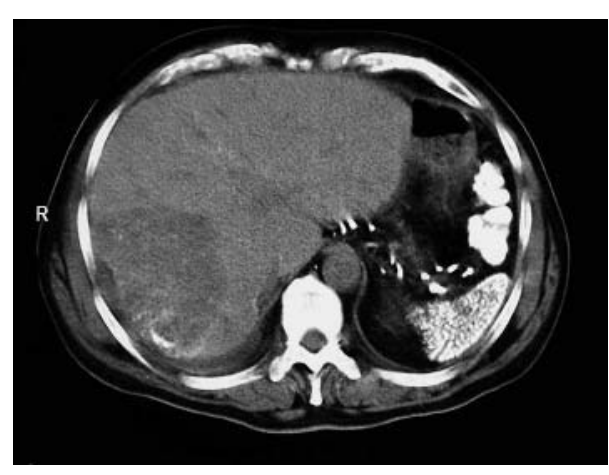

Figure 1 Computed tomography of an unenhanced section through the right lobe of the liver and spleen.

This case is submitted by:

D C Howlett, M Segwagwe, N D P Marchbank, A A Dunk Eastbourne District General Hospital, Eastbourne, East Sussex, UK

Correspondence to: Dr D C Howlett, Eastbourne District General Hospital, Kings Drive, Eastbourne, East Sussex BN21 2UD, UK; David.Howlett@ESHT.NHS.UK

doi: 10.1136/gut.2004.055962 